\title{
CORONARY ARTERIAL PERFUSION DURING VENOARTERIAL EXTRACORPOREAL MEMBRANE OXYGENATION
}

Junji Kato, MD

Takahiko Seo, MD, PhD

Hisami Ando, MD, $\mathrm{PhD}$

Hiroyuki Takagi, MD, $\mathrm{PhD}$

Takahiro Ito, MD, PhD
The effects of venoarterial extracorporeal membrane oxygenation on left ventricular performance have not been studied in detail. Coronary arterial flow obtained by direct measurement with an electromagnetic flowmeter and blood gas analysis from the aortic root were tabulated during venoarterial extracorporeal membrane oxygenation in 14 puppies, and these parameters were evaluated with respect to changes in the venoarterial extracorporeal membrane oxygenation flow. Unique automatic blood pumps generating pulsatile flow were used for the venoarterial extracorporeal membrane oxygenation bypass. Coronary arterial flow decreased as the extracorporeal membrane oxygenation flow increased $(106 \pm 26 \mathrm{ml} / \mathrm{min}$ per $100 \mathrm{gm}$ of left ventricle at 20 $\mathrm{ml} \cdot \mathrm{min}^{-1} \cdot \mathrm{kg}$ bypass flow to $71 \pm 17 \mathrm{ml} / \mathrm{min}$ per $100 \mathrm{gm}$ of left ventricle at $100 \mathrm{ml} \cdot \mathrm{min}^{-1} \cdot \mathrm{kg}$ bypass flow, $p<0.01$ ). There were no significant changes in the mean or diastolic pressures in the ascending aorta despite changes in the extracorporeal membrane oxygenation flow. Arterial oxygen tension in the ascending aorta was not increased even under high-flow venoarterial extracorporeal membrane oxygenation. This result indicates that oxygenated blood from the extracorporeal membrane oxygenation circuit does not pass in a retrograde fashion into the aortic root and thus does not perfuse the coronary arteries. The diastolic aortic pressure did not correlate with the changes in extracorporeal membrane oxygenation flow. The decrease in coronary arterial flow is therefore predominantly caused by increased coronary arterial resistance. Tension-time index, an indicator of myocardial oxygen consumption, did not decrease with venoarterial extracorporeal membrane oxygenation. In conclusion, high-flow venoarterial extracorporeal membrane oxygenation causes undesirable hemodynamic effects on the left ventricle. (J THORAC CARDIOVASC Surg 1996;111:630-6)
V enoarterial extracorporeal membrane oxygenation (VA-ECMO) is a widely accepted lifesupport measure for neonates with life-threatening respiratory failure. Although its obvious benefit for respiratory function cannot be denied, the effects of VA-ECMO on left ventricular performance have not been delineated. In previous experimental stud-

From the Department of Surgery, Branch Hospital, Nagoya University School of Medicine, Nagoya, Japan.

Supported in part by a Grant-in-Aid for Scientific Research $(6348039,2557053)$ from the Japanese Ministry of Education, Science, and Culture.

Received for publication March 8, 1995; accepted for publication June 28, 1995.

Address for reprints: Takahiro Ito, MD, Department of Surgery, Branch Hospital, Nagoya University School of Medicine, Daikohminami 1-1-20, Higashi-ku, Nagoya 461, Japan.

Copyright (C) 1996 by Mosby-Year Book, Inc.

$0022-5223 / 96 \$ 5.00+0 \quad \mathbf{1 2 / 1 / 6 7 3 8 6}$ ies, we showed that the LVEDP increases and cardiac output decreases as the extracorporeal membrane oxygenation (ECMO) flow increases during VA-ECMO. ${ }^{1}$ These findings are indicative of the possible undesirable effects of VA-ECMO on left ventricular function.

The purpose of this study was to determine the effects of VA-ECMO on coronary arterial flow (CAF) by means of direct measurement with an electromagnetic flowmeter. In addition, the question of whether the left ventricle was perfused directly by retrograde flow in the ascending aorta from the ECMO circuit was investigated by analyzing oxygen tension in the aortic root.

\section{Materials and methods}

Devices and driving systems. The ECMO circuit consists of a self-regulating blood pump (the Takagi pump ${ }^{2}$ ) and a silicone hollow-fiber membrane oxygenator with a 


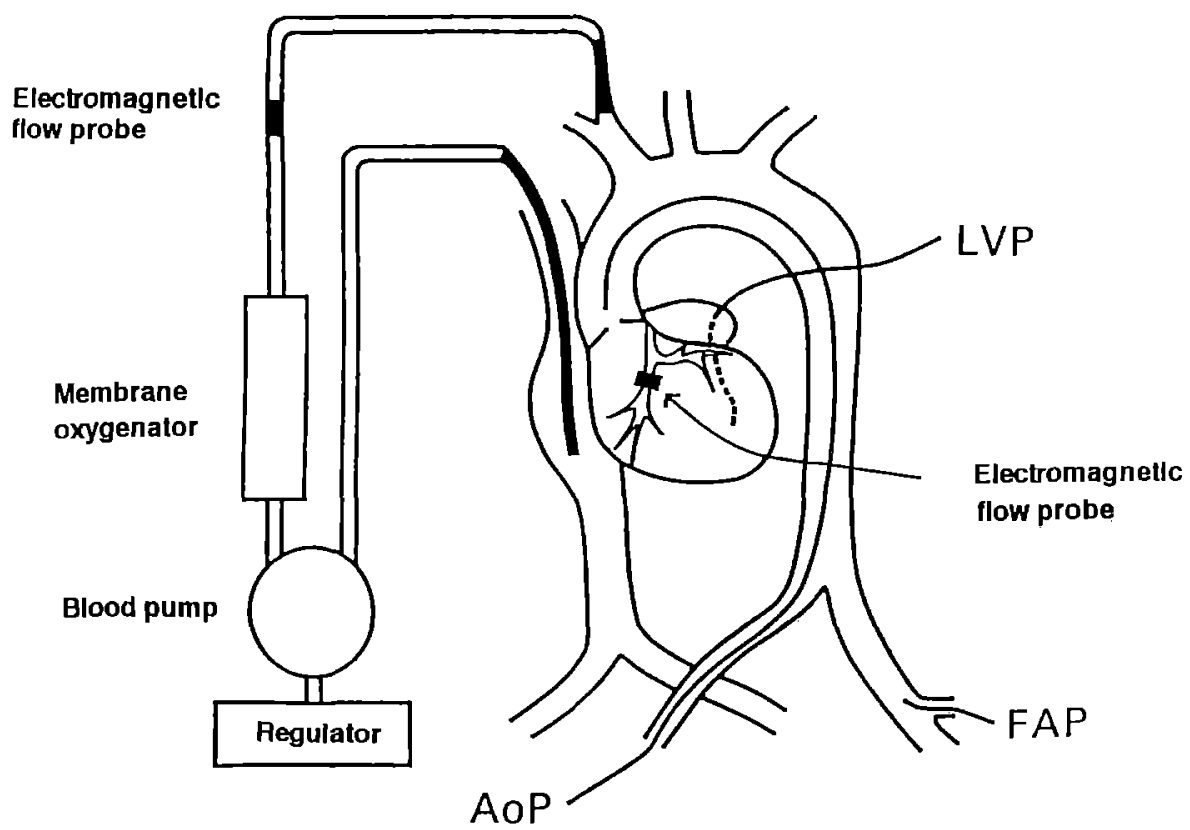

Fig. 1. Schematic diagram of the VA-ECMO circuit and experimental model. Note the placement of the electromagnetic flow probe on the coronary artery and the cannulation sites for hemodynamic measurements.

surface area of $0.5 \mathrm{~m}^{2}$ (MERASILOX-S; Senkoh Ika Kogyo Inc., Tokyo, Japan). A pair of sack-type pumps are driven in alternation by compressed air under automatic control. The ECMO flow, which is monitored with an electromagnetic flowmeter, is automatically regulated by changes in pumping rates and driving air pressure of the pump in response to hemodynamic changes of the body. ${ }^{1,3,4}$ Because venous blood drains only by gravity and the pump does not generate as much excessive negative pressure as a roller pump does, no venous reservoir is necessary and the total priming volume of the ECMO circuit is only $65 \mathrm{ml}$. Our sack-type pump produces pulsatile flow; it has been used for purposes of automatic regulation of the ECMO flow, however, not for the pulsatile flow. Moreover, the membrane oxygenator has a large pressure resistance and the pulse pressure generated by the pump is reduced to $20 \%$ through the membrane oxygenator. ${ }^{1}$ The flow at the arterial site of the circuit thus resembles continuous flow produced by a roller pump, so the pumping of our ECMO circuit may not be synchronized with the natural beating heart.

Materials. Fourteen small mongrel dogs with a mean weight of $3.5 \mathrm{~kg}$ (range 2.6 to $5.0 \mathrm{~kg}$ ) were studied. All experiments were performed in accordance with the "Animal Experimental Guide-Nagoya University School of Medicine" (Nagoya University, revised in 1989). The animals received humane care in compliance with the "Principles of Laboratory Animal Care" formulated by the National Society for Medical Research and the "Guide for the Care and Use of Laboratory Animals" prepared by the Institute of Laboratory Animal Resources and published by the National Institutes of Health (NIH Publication No. 86-23, revised 1985).
Methods. The animals were anesthetized with thiamylal sodium $(10 \mathrm{mg} / \mathrm{kg})$. They were then intubated, ventilated, and subjected to general endotracheal anesthesia with continuous intravenous ketamine chloride $(10 \mathrm{mg} / \mathrm{kg}$ per hour) and pancuronium bromide $(0.1 \mathrm{mg} / \mathrm{kg}$ per hour). Blood products were not administered during the study except for priming of the ECMO circuit with fresh blood. Ventilator settings were reduced to achieve respiratory rates of 10 breaths/min and peak inspiratory pressures of $10 \mathrm{~cm} \mathrm{H}_{2} \mathrm{O}$ with room air before the start of VA-ECMO, and these settings were maintained during VA-ECMO.

An inflow catheter was inserted into the right atrium through the right external jugular vein (Fig. 1). An outflow catheter was inserted into the common carotid artery. The mediastinum was entered through a median sternotomy and the heart was suspended in the pericardial cradle. A 22-gauge catheter was inserted into a branch of the left femoral artery to measure the femoral arterial systemic pressure (FAP). A 5F polyethylene catheter was passed through the right femoral artery with its tip positioned just above the sinus of Valsalva for measurement of the ascending aortic pressure $(\mathrm{AoP})$ and procurement of blood samples. Left ventricular pressure (LVP) was monitored with a $3 \mathrm{~F}$ transauricular catheter. A continuous electrocardiogram was recorded. The hemodynamic parameters were monitored with pressure transducers (P23ID; Gould, Inc., Oxnard, Calif.) and recorded on a multichannel polygraph (Polygraph 363; NEC-Sanei Inc., Tokyo, Japan). Blood samples were drawn from the left ventricle, ascending aorta, and femoral artery for blood gas determination with a gas analyzer (NOVA SP5; NOVA Biomedical Corporation, Waltham, Mass.). The tension- 
Table I. Hemodynamic parameters before and during VA-ECMO

\begin{tabular}{|c|c|c|c|c|c|c|}
\hline & \multicolumn{6}{|c|}{$V A-E C M O$ flow $\left(\mathrm{ml} \cdot \mathrm{min}^{-1} \cdot \mathrm{kg}^{-1}\right)$} \\
\hline & 0 & 20 & 40 & 60 & 80 & 100 \\
\hline $\mathrm{CAF}(\mathrm{ml} / \mathrm{min}$ per $100 \mathrm{gm} \mathrm{LV})$ & $135 \pm 46$ & $106 \pm 26$ & $96 \pm 20$ & $89 \pm 22$ & $77 \pm 18$ & $71 \pm 17^{*}$ \\
\hline Systolic LVP (mm Hg) & $125 \pm 41$ & $111 \pm 33$ & $107 \pm 35$ & $102 \pm 37$ & $94 \pm 35$ & $93 \pm 30^{*}$ \\
\hline \multicolumn{7}{|l|}{$\mathrm{AoP}(\mathrm{mm} \mathrm{Hg})$} \\
\hline Systolic & $100 \pm 23$ & $85 \pm 11$ & $84 \pm 15$ & $80 \pm 17$ & $78 \pm 19$ & $78 \pm 20$ \\
\hline Diastolic & $72 \pm 6$ & $53 \pm 14$ & $56 \pm 14$ & $56 \pm 16$ & $56 \pm 18$ & $56 \pm 21$ \\
\hline Mean & $84 \pm 24$ & $66 \pm 14$ & $68 \pm 14$ & $66 \pm 17$ & $66 \pm 18$ & $65 \pm 21$ \\
\hline Mean FAP (mm Hg) & $83 \pm 29$ & $64 \pm 14$ & $66 \pm 14$ & $64 \pm 17$ & $63 \pm 19$ & $63 \pm 21$ \\
\hline TTI $(\%)$ & 100 & $93 \pm 18$ & $102 \pm 24$ & $99 \pm 22$ & $99 \pm 24$ & $102 \pm 35$ \\
\hline
\end{tabular}

Data mean \pm standard deviation; $n=14 . L V$, Left ventricle.

*Statistical significance compared with value at flow rate of $20 \mathrm{ml} \cdot \mathrm{min}^{-1} \cdot \mathrm{kg}^{-1}(p<0.01)$.

time index (TTI) was computed from data obtained through planimetry of the systolic phase by means of the LVP tracings. TTI was determined by calculation of the area beneath the systolic portion of the LVP curve tracings. 5,6

CAF was measured with an electromagnetic flowmeter (FJ-015T; Nihon Kohden Inc., Tokyo, Japan). A flow probe was placed on the left anterior descending coronary artery. Because $45 \%$ of the total coronary blood flow is distributed to the left anterior descending artery, ${ }^{7}$ the total CAF was estimated from the measured CAF on the left anterior descending artery and expressed per $100 \mathrm{gm}$ wet weight of the left ventricle. Coronary vascular resistance was calculated by dividing mean AoP by total CAF.

After VA-ECMO was initiated between the right atrium and the right common carotid artery, the flow was increased in $20 \mathrm{ml} \cdot \mathrm{min}^{-1} \cdot \mathrm{kg}^{-1}$ increments to a maximum bypass flow of $100 \mathrm{ml} \cdot \mathrm{min}^{-1} \cdot \mathrm{kg}^{-1}$. In nine of the 14 animals, the flow was then decreased in $20 \mathrm{ml}$. $\mathrm{min}^{-1} \cdot \mathrm{kg}^{-1}$ increments to a bypass flow of zero. All measurements were made after a 5-minute stabilization period at each flow rate.

Statistical analysis. Results are expressed as mean \pm standard deviation. Analysis of variance and the paired $t$ test were used to analyze the data. Differences were considered statistically significant at a $p$ value less than 0.05 .

\section{Results}

CAF. CAF increased significantly with reduced ventilator settings and decreased significantly shortly after the initiation of ECMO (Table I). CAF continued to fall with increases in the ECMO flow (Fig. 2). As the ECMO flow was decreased from the maximum of $100 \mathrm{ml} \cdot \mathrm{min}^{-1} \cdot \mathrm{kg}^{-1}$ to $20 \mathrm{ml}$. $\min ^{-1} \cdot \mathrm{kg}^{-1}$, CAF increased and eventually returned to baseline. CAF was thus inversely proportional to the ECMO flow.

LVP, AoP, and FAP. LVP decreased when the ECMO flow was increased to greater than $80 \mathrm{ml}$. $\min ^{-1} \cdot \mathrm{kg}^{-1}$ (Table I). The systolic AoP also decreased gradually after the initiation of ECMO.
After a rapid fall shortly after the initiation of ECMO, the diastolic and mean AoPs remained low. The mean FAP exhibited a pattern of changes similar to those in the mean AoP. None of these changes, however, were statistically significant.

Blood gas analyses. Low pre-ECMO arterial oxygen tension $\left(\mathrm{PaO}_{2}\right)$ in the left ventricle, ascending aorta, and femoral artery resulted from reduced ventilator settings. As the ECMO flow was increased to greater than $60 \mathrm{ml} \cdot \mathrm{min}^{-1} \cdot \mathrm{kg}^{-1}, \mathrm{PaO}_{2}$ in the femoral artery increased significantly (76 \pm $29 \mathrm{~mm} \mathrm{Hg}$ before ECMO to $174 \pm 80 \mathrm{~mm} \mathrm{Hg}$ at $60 \mathrm{ml} \cdot \min ^{-1} \cdot \mathrm{kg}^{-1}, \mathrm{p}<0.01$; Fig. 3). On the other hand, $\mathrm{PaO}_{2}$ in the left ventricle and ascending aorta did not change significantly. The disparity in $\mathrm{PaO}_{2}$ at the different sites became more prominent as the ECMO flow was increased to $100 \mathrm{ml} \cdot \mathrm{min}^{-1} \cdot \mathrm{kg}^{-1}$. The difference in $\mathrm{PaO}_{2}$ between the left ventricle and ascending aorta was not significant. The ascending aorta was thus perfused by blood that had been ejected by the left ventricle. There were no significant changes in arterial carbon dioxide tension at the different ECMO flow rates or at the different sites.

TTI. TTI at a bypass flow of $20 \mathrm{ml} \cdot \mathrm{min}^{-1} \cdot \mathrm{kg}^{-1}$ was 7\% less than the level before ECMO; however, TTI was not significantly different from baseline with ECMO flow rates greater than $40 \mathrm{ml}$. $\min ^{-1} \cdot \mathrm{kg}^{-1}$ (Table I). Myocardial oxygen consumption is thus not reduced despite the bypassing of blood from the heart with the VA-ECMO circuit.

Coronary vascular resistance. Coronary vascular resistance at a bypass flow of $20 \mathrm{ml} \cdot \mathrm{min}^{-1} \cdot \mathrm{kg}^{-1}$ was $20 \mathrm{~mm} \mathrm{Hg} \cdot \mathrm{ml}^{-1} \cdot \min ^{-1}$ per $100 \mathrm{gm} \mathrm{left}$ ventricle less than the level before VA-ECMO. Coronary vascular resistance rose significantly, however, with an increase in bypass flow (Fig. 4). 


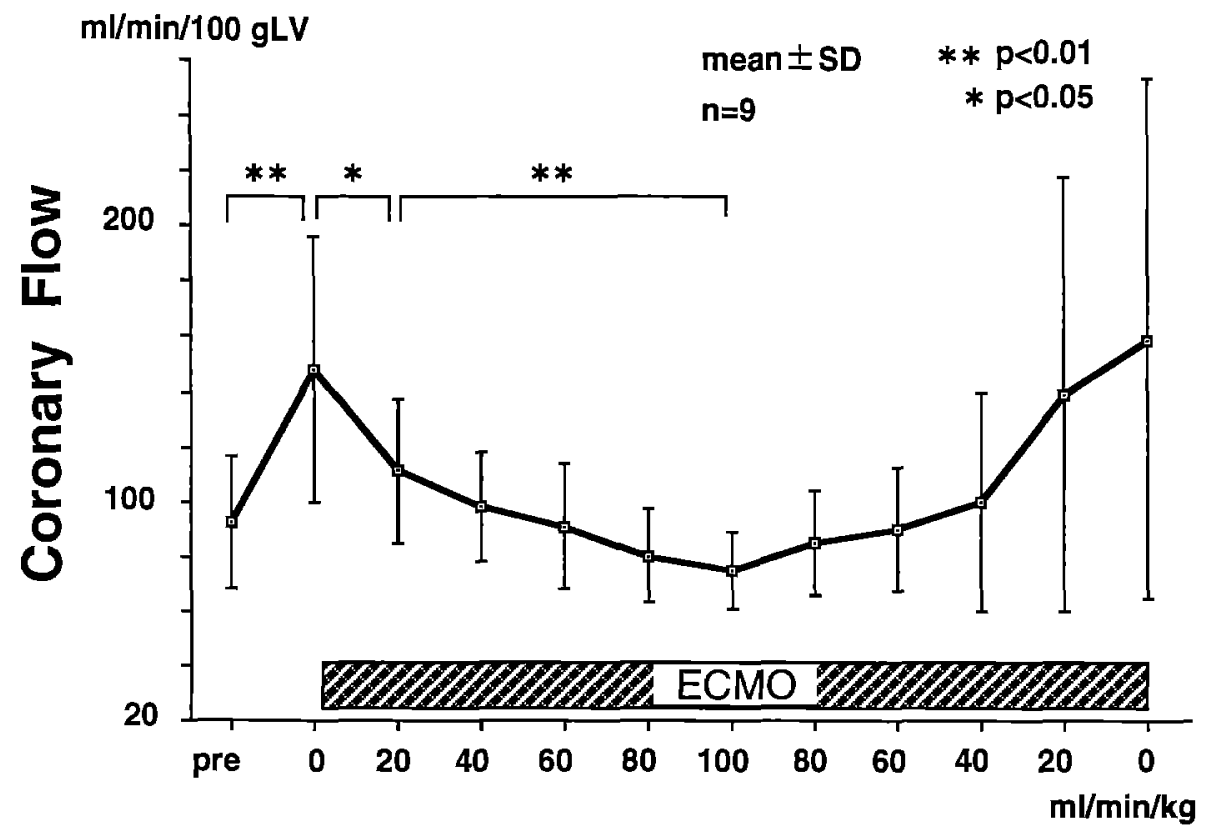

\section{Bypass Flow}

Fig. 2. CAF as a function of bypass flow. Ventilation settings were reduced to $10 \mathrm{~cm} \mathrm{H}_{2} \mathrm{O}$ peak inspiratory pressure and 10 breaths/min respiratory rate between period before VA-ECMO (pre) and the initiation of VA-ECMO. CAF increased significantly with reduced ventilator settings and decreased significantly shortly after the initiation of ECMO. CAF continued to fall with increases in the ECMO flow. As the ECMO flow was decreased from the maximum of $100 \mathrm{ml} \cdot \mathrm{min}^{-1} \cdot \mathrm{kg}^{-1}$ to $20 \mathrm{ml} \cdot \mathrm{min}^{-1} \cdot \mathrm{kg}^{-1}$, CAF increased to the same level as before VA-ECMO. $g L V$, Grams of left ventricle, wet weight; $S D$, standard deviation.

\section{Discussion}

The effect of VA-ECMO on cardiac performance may play a significant role in determining outcome in critically ill children. Unfortunately, this important issue has not previously been studied in detail. In particular, myocardial oxygen consumption and CAF during VA-ECMO have not been delineated. Only recently has the regional blood flow to the heart during ECMO been discussed on the basis of studies with isotope-labeled microspheres ${ }^{8-10}$ or Doppler ultrasonography. ${ }^{11}$ This study is the first to determine CAF during VA-ECMO, as directly measured by an electromagnetic flowmeter. The observation that coronary perfusion is significantly reduced during VA-ECMO is in agreement with conclusions from previous studies with the radiolabeled microsphere technique. ${ }^{8,9}$ Smith and associates $^{8}$ studied the relative blood flow of the various organs in lambs by counting isotope-labeled albumin injected from the perfusion cannula and concluded that the relative coronary blood flow from the cannula was significantly less than that in the control group. Nowlen and coworkers ${ }^{9}$ used a simi- lar isotope method in rabbits during ECMO; they injected the isotope from the ventricle and the perfusion cannula. Their data suggest that perfusion of the heart is significantly reduced during low-flow ECMO. These two interesting studies did not evaluate the relationship between the ECMO flow rate and $\mathrm{CAF}$.

Coronary blood flow is regulated by a variety of factors, including perfusion pressure of the coronary artery, myocardial oxygen demand, coronary arterial resistance, elasticity of the aortic bulb, and autoregulation. ${ }^{12}$ The coronary perfusion pressure depends on the pressure both in the aortic root and at the coronary sinus. Because the progressive decrease in CAF during ECMO was not accompanied by any significant decrease in the aortic root pressure, it seems unlikely that a decrease in the perfusion pressure was the cause of the drop in CAF. When the heart is bypassed with VA-ECMO or left heart bypass, there should be a lower myocardial oxygen demand. This would result in a compensatory decrease in CAF. Early studies of the left ventricular assist device revealed no significant changes in cor- 


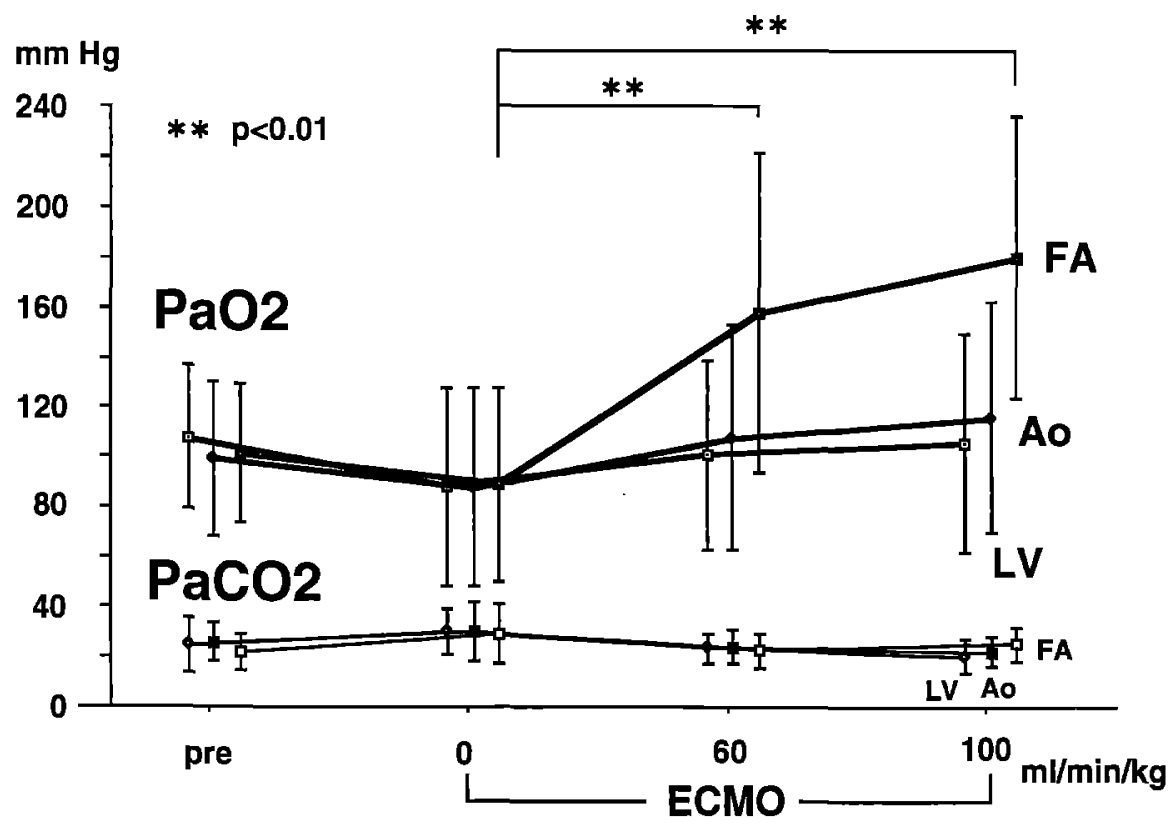

Fig. 3. Blood gas analysis during VA-ECMO. $\mathrm{PaO}_{2}$ and arterial carbon dioxide tension $\left(\mathrm{PaCO}_{2}\right)$ were measured in blood obtained from the femoral artery $(F A)$, ascending aorta $(A o)$, and left ventricle $(L V)$. A low PaO ${ }_{2}$ before ECMO (pre) in the FA resulted from reduced ventilator settings. $\mathrm{PaO}_{2}$ in the FA increased significantly with ECMO flows greater than 60 $\mathrm{ml} \cdot \min ^{-1} \cdot \mathrm{kg}^{-1}$. There were no significant changes in $\mathrm{PaO}_{2}$ in the $\mathrm{LV}$ or Ao. The disparity in $\mathrm{PaO}_{2}$ among the different sites became more prominent as the ECMO flow was increased to $100 \mathrm{ml} \cdot \mathrm{min}^{-1} \cdot \mathrm{kg}^{-1}$. There were no significant changes in $\mathrm{PaCO}_{2}$ at the different ECMO flow rates or at the different sites.

onary blood flow or myocardial oxygen consumption. ${ }^{13-15}$ On the contrary, others have reported decreases in coronary flow and significant reductions in myocardial oxygen consumption. ${ }^{5,16}$ With implementation of ECMO, we noted no significant change in TTI, which has been used as an indicator of myocardial oxygen consumption. ${ }^{6}$ The observed decrease in $\mathrm{CAF}$ cannot be explained by a decrease in myocardial oxygen demand.

Coronary vascular resistance increased as the ECMO flow increased (Fig. 4). Increased extravascular resistance caused by elevated myocardial tissue pressure may account for the increased coronary vascular resistance during high-flow VA-ECMO. A Doppler echocardiographic study of neonates undertaken by Martin and colleagues ${ }^{17}$ revealed that left ventricular end-systolic wall stress increases during VA-ECMO. The increase in left ventricular wall stress could be responsible for the increase in coronary vascular resistance during VA-ECMO. Bavaria and coworkers ${ }^{18}$ have studied the effects of ECMO on the normal and ischemic heart in sheep by using ultrasonic crystals to measure changes in left ventricular wall thickness and left ventricular volume. They showed that as ECMO flow increased the end-diastolic volume decreased. In addition, ECMO produced small decreases in ventricular volume in normal hearts. Such small decreases resulted in no changes in the LVP. In previous studies, we have shown an increase in LVEDP during high-flow ECMO and have speculated that this could result in an increase in coronary vascular resistance and consequent decrease in coronary flow. ${ }^{1}$

The expanded aorta acts as a reservoir for the delivery of blood to the heart during diastole, when the coronary arteries are perfused. Absence or minimization of pulsation during VA-ECMO may lead to incompetent reservoir function of the aortic root. Such impaired reservoir function of the expanded aorta, caused partially by the decrease in cardiac output, may also contribute to the decrease in CAF. According to Grattan and associates, ${ }^{19}$ who conducted Doppler echocardiographic studies in infants placed on ECMO, cardiopulmonary bypass abolishes the normal autoregulation of coronary flow and can result in "coronary steal syndrome." Kjekshus, ${ }^{20}$ who observed the loss of autoregulation 


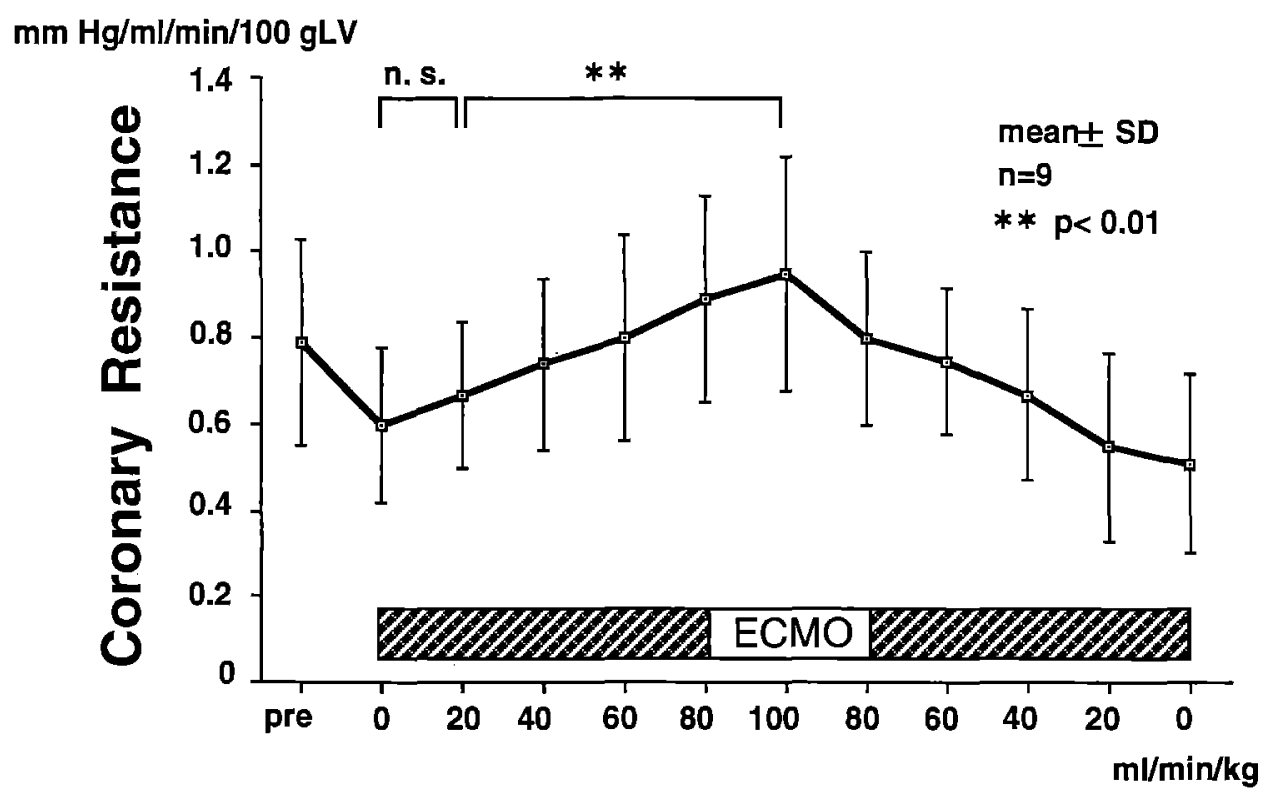

\section{Bypass Flow}

Fig. 4. Coronary resistance as a function of bypass flow. The coronary resistance decreased with reduced ventilator settings and increased with increases in bypass flow. The difference in coronary resistance between the peak ECMO flow $\left(100 \mathrm{ml} \cdot \mathrm{min}^{-1} \cdot \mathrm{kg}^{-1}\right)$ and minimal ECMO flow $\left(20 \mathrm{ml} \cdot \mathrm{min}^{-1} \cdot \mathrm{kg}^{-1}\right)$ was statistically significant $(\mathrm{p}<0.01)$. The coronary resistance returned to baseline as the bypass flow was decreased. $g L V$, Grams of left ventricle, wet weight; $S D$, standard deviation.

of the coronary flow with increases in LVEDP, reported that the increased ventricular filling pressure can impede coronary flow during diastole in the ischemic heart. The significance of these effects on CAF during VA-ECMO could not be discerned.

The lack of an obvious increase in $\mathrm{PaO}_{2}$ in the ascending aorta with high-flow VA-ECMO indicates that the coronary arteries were perfused mainly with blood ejected from the left ventricle. There was no evidence of direct retrograde flow of the well-oxygenated blood to the coronary arteries from the VAECMO circuit. In addition, cardiac output is decreased in inverse proportion to the ECMO flow. ${ }^{1,8,9}$ In a Doppler ultrasonographic study of neonates, Walther and colleagues ${ }^{11}$ reported that a significant decrease in the left and right ventricular output is proportional to the amount of bypass flow provided as well as to the decrease in left ventricular contractility. A marked decrease in cardiac performance reported in some infants placed on ECMO has been termed "cardiac stun syndrome." 21 It is likely that the heart does not receive an adequate supply of oxygen because of the reduced CAF and lack of direct supply of oxygenated blood from the VA-ECMO circuit.

Asynchronous flow and a pulse pressure gener- ated by an extracorporeal circuit may also impede pulsatile aortic blood flow during high-flow VAECMO. The pulse pressure generated by our pump, however, is reduced to $20 \%$ through the membrane oxygenator. ${ }^{1}$ Pulsatile flow of this magnitude without synchronization in our ECMO circuit does not appear to exert much influence on the function of the natural beating heart.

In conclusion, CAF decreases as VA-ECMO flow increases. In addition, oxygenated blood from the ECMO circuit does not pass in a retrograde fashion from the ascending aorta to the coronary arteries. Coronary perfusion is thus derived only from blood ejected by the left ventricle. High-flow VA-ECMO therefore exerts undesirable hemodynamic effects on the left ventricle. Similar findings would presumably apply to cardiopulmonary bypass for cardiac operations, specifically when bypass is initiated and, more important, when the patient is weaned from bypass to spontaneous cardiac support. In our study, we used the canine model with intact cardiac function. Further study is needed to assess left ventricular performance and CAF in an experimental model with a left ventricle compromised by ischemic insult or high-dose $\beta$ blockade. 
We thank I. Kanamoto, MD, of the Chayagasaka Animal Hospital for his expert advice concerning animal care and anesthesia in puppies and R. Sasaki, MD, of the Department of Preventive Medicine, Nagoya University School of Medicine, for his advice on the statistical analysis.

\section{REFERENCES}

1. Seo T, Ito T, Iio K, Kato J, Takagi H. Experimental study on the hemodynamic effects of veno-arterial extracorporeal membrane oxygenation with an automatically driven blood pump on puppies. Artif Organs 1991;15:402-7.

2. Takagi $H$, Hotta $T$, Tamura $M$, Ohta $K$. Left ventricular aortic bypass in dogs with double chambered alternating pumping system. Artif Organs 1978;2:182-5.

3. Ito $\mathrm{T}$, Takagi $\mathrm{H}$, Seo $\mathrm{T}$. New neonatal and pediatric venoarterial extracorporeal membrane oxygenation circuit using automatically driven blood pumps. Artif Organs 1990;14: 186-8.

4. Seo $T$, Ito $T$, Ishiguro $Y$, Takagi $H$. New neonatal extracorporeal membrane oxygenation circuit with a self-regulating blood pump. Surgery 1994;115:463-72.

5. Miller DR. Comparative effects of left atrial or left ventricular bypass on coronary sinus flow and oxygen usage in dogs. Ann Surg 1974;179:830-5.

6. Sarnoff SJ, Braunwald E, Welch GH, Case RB, Stainsby WN, Macruz R. Hemodynamic determinants of oxygen consumption of the heart with special reference to the tension-timeindex. Am J Physiol 1958;192:148-56.

7. Takiya H. Experimental study of pulsatile assist device: Effects on cardiac function and myocardial metabolism. J Jpn Assoc Thorac Surg 1981;29:1625-34

8. Smith HG, Whittlesey GC, Kundu S, et al. Regional blood flow during extracorporeal membrane oxygenation in lambs. Trans Am Soc Artif Intern Organs 1989;35:657-60.

9. Nowlen TT, Salley SO, Whittlesey GC, et al. Regional blood flow distribution during extracorporeal membrane oxygenation in rabbits. J THORAC CARdIOVASC SURG 1989;98:113843.
10. Kinsella JP, Gerstmann DR, Rosenberg AA. The effect of extracorporeal membrane oxygenation on coronary perfusion and regional blood flow distribution. Pediatr Res 1992;31: 80-4.

11. Walther FJ, Bor M, Gangitano ES, Snyder JR. Left and right ventricular output in newborn infants undergoing extracorporeal membrane oxygenation. Crit Care Med 1990;18:14851.

12. Rubio R. Regulation of coronary blood flow. Progr Cardiovasc Dis 1975;18:105-22.

13. Sato T, Glenn WWL. Effect of left heart bypass on left ventricular function and coronary blood flow. Surgery 1970; 68:314-22

14. Schenk WG, Delin NA, Camp FA, et al. Assisted circulation: an experimental evaluation of counterpulsation and left ventricular bypass. Arch Surg 1964;88:327-41.

15. Wakabayashi K, Kubo T, Gilman P, Zuber WF, Connolly JE. Oxygen consumption of the normal and failing heart during left heart bypass. J Thorac CardiovasC Surg 1975;70:9-18.

16. Dennis C, Hall DP, Moreno JR, Senning A. Reduction of the oxygen utilization of the left heart bypass. Circ Res 1962;10: 298-305.

17. Martin GR, Short BL. Doppler echocardiographic evaluation of cardiac performance in infants on prolonged extracorporeal membrane oxygenation. Am J Cardiol 1988;62:929-34.

18. Bavaria JE, Ratcliffe MB, Gupta KB, Wenger RK, Bogen DK, Edmunds LH. Changes in left ventricular systolic wall stress during biventricular circulatory assistance. Ann Thorac Surg 1988;45:526-32.

19. Grattan MT, Bear RW, Hanley FL, Messina LM, Turley K, Hoffman JIE. The effects of cardiopulmonary bypass on coronary blood flow in the dog. J THORAC CARDIOvaSC SURG 1984;88:982-92.

20. Kjekshus JK. Mechanism for flow distribution in normal and ischemic myocardium during increased ventricular preload in the dog. Circ Res 1973;33:489-99.

21. Martin GR, Short BL, Abbott C, O'Brien AM. Cardiac stun in infants undergoing extracorporeal membrane oxygenation. J THORAC CARDIOVASC SURG 1991;101:607-11.

\section{1-800-55-MOSBY}

This number links you to the full text of articles published in over 25,000 journals, including all Mosby journals. MOSBY Document Express $^{\circledR}$, a rapid response information retrieval service, provides quick turnaround, 24-hour availability, and speedy delivery methods. For inquiries and pricing information, call our toll-free, 24-hour order line: 1-800-55-MOSBY; outside the United States: 415-259-5046; fax: 415-259-5019; E-mail: mosbyexp@class.org. 